\title{
Recent Trends in Integrated Biorefineries Development for Sustainable Production
}

\author{
Diego T. Santos, ${ }^{1,2}$ Adriano V. Ensinas, ${ }^{2}$ Anuj K. Chandel, ${ }^{3}$ \\ François Maréchal, ${ }^{2}$ and M. Angela A. Meireles ${ }^{1}$ \\ ${ }^{1}$ School of Food Engineering (LASEFI/DEA/FEA), University of Campinas (UNICAMP), Cidade Universitária "Zeferino Vaz," \\ Rua Monteiro Lobato, 80, 13083-862 Campinas, SP, Brazil \\ ${ }^{2}$ Industrial Process and Energy Systems Engineering (IPESE), Swiss Federal Institute of Technology Lausanne (EPFL), \\ Station 9, 1015 Lausanne, Switzerland \\ ${ }^{3}$ Department of Chemical Engineering, University of Arkansas, 3202 Bell Engineering Center, Fayetteville, AR 72701-1201, USA
}

Correspondence should be addressed to Diego T. Santos; diego_tresinari@yahoo.com.br

Received 21 September 2014; Accepted 21 September 2014; Published 9 November 2014

Copyright (C) 2014 Diego T. Santos et al. This is an open access article distributed under the Creative Commons Attribution License, which permits unrestricted use, distribution, and reproduction in any medium, provided the original work is properly cited.

Biorefinery applications gather several important and diverse fields of research: biofuels production, process engineering, biotechnology, agronomy, and environmental impact assessment, among others. The highly interdisciplinary dimension of the biorefinery concept makes it extremely difficult to have an overview of the research activities in this field. Moreover, the diversity of pretreatment, conversion, and separation processes to transform biomass into value-added chemicals and biofuels is immensely important. Furthermore, there is lack of concrete information to fill the gap and build the necessary interface between research laboratories and industries (chemical industries, forestry industries, and food industries). This will foster the right kind of environment for the harnessing of the fullest potential of biomass into valuable products while providing employment and safe environment.

This special issue presents a diverse range of advancements focused on the design and development of integrated facilities aiming at the production of multiple products from biomass ( 3 articles) and industrial effluents ( 2 articles). Authors here reported the potential of mix feedstocks to yield a wide range of products by employing a combination of technologies (e.g., chemical and/or biological transformations and separations) in integrated biorefineries. Fourteen contributions were peer-reviewed and revised in order to meet the standards for publication in the journal, with five articles being accepted for inclusion in this especial issue: three articles related to the use of biomass fractions aiming at the production of multiple products and two articles discussing the use of industrial effluents adapting biorefinery concepts.

The fractionation of lignocellulosic materials is addressed in three manuscripts. J. K. Kurian et al. performed experimental study on calcium hydroxide-assisted delignification of hydrothermally treated sweet sorghum bagasse. The paper by F. A. F. Antunes et al. explores the use of dilute acid hydrolysis as the fractionation method to obtain a sugarcane bagasse hemicellulosic hydrolysate. In their study, ethanol production performance of novel xylose-fermenting yeast, Scheffersomyces shehatae UFMG-HM 52.2, was evaluated under batch fermentation conditions using sugarcane bagasse hemicellulosic hydrolysate as carbon source. J. Q. Albarelli et al. compared two fractionation technologies (liquid hot water and steam explosion) using simulation tools in a biorefinery producing ethanol from sugarcane juice and second generation ethanol production using a new raw material: sugarcane bagasse fine fraction composed of parenchyma cells (P-fraction).

Two of the manuscripts deal with the use of industrial effluents, evaluating the possibility to minimize the use of water with wastewater treatment with the integration of this process to others aiming at the development of sustainable integrated biorefineries. M. Berni et al. discuss 
the perspectives of treating effluents through anaerobic digestion using an up-flow anaerobic sludge blanket (UASB) reactor as biorefinery annex in a pulp and paper industrial plant to be burned in the boilers. The paper by Â. P. Matos et al. evaluates experimentally the cultivation of microalgae using wastewater from the desalination process of groundwater. They studied the influence of dilution rate on the continuous cultivation to establish relationship between the desalination wastewater and protein/lipid contents along with fatty acid distribution in continuously cultivated Chlorella vulgaris.

The editors of this special issue would like to thank the contributing authors for sharing their quality research through this special issue and the reviewers for their critical comments and suggestions which helped to improve the quality of the articles.

By compiling these articles, we have attempted to disseminate the key information on recent trends in integrated biorefineries development for sustainable production of bioenergy and bioremediation.

Diego T. Santos

Adriano V. Ensinas

Anuj K. Chandel

François Maréchal

M. Angela A. Meireles 

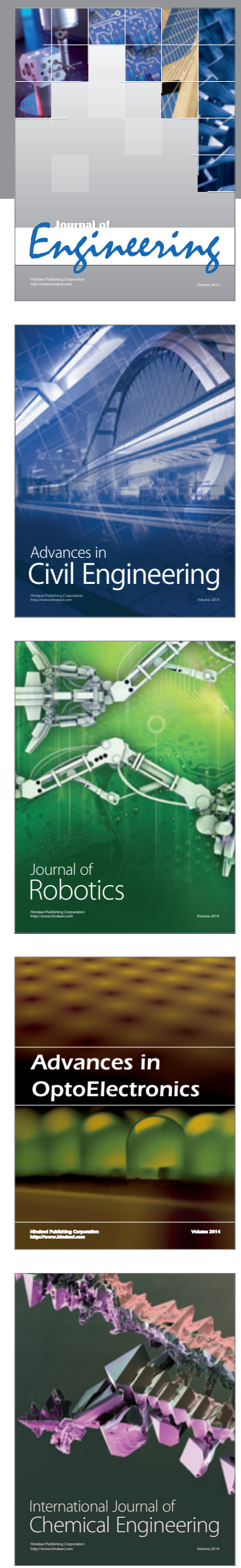

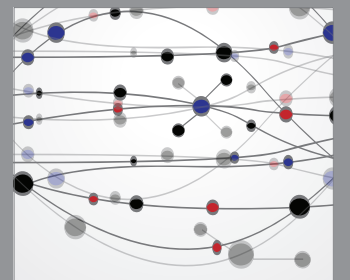

The Scientific World Journal
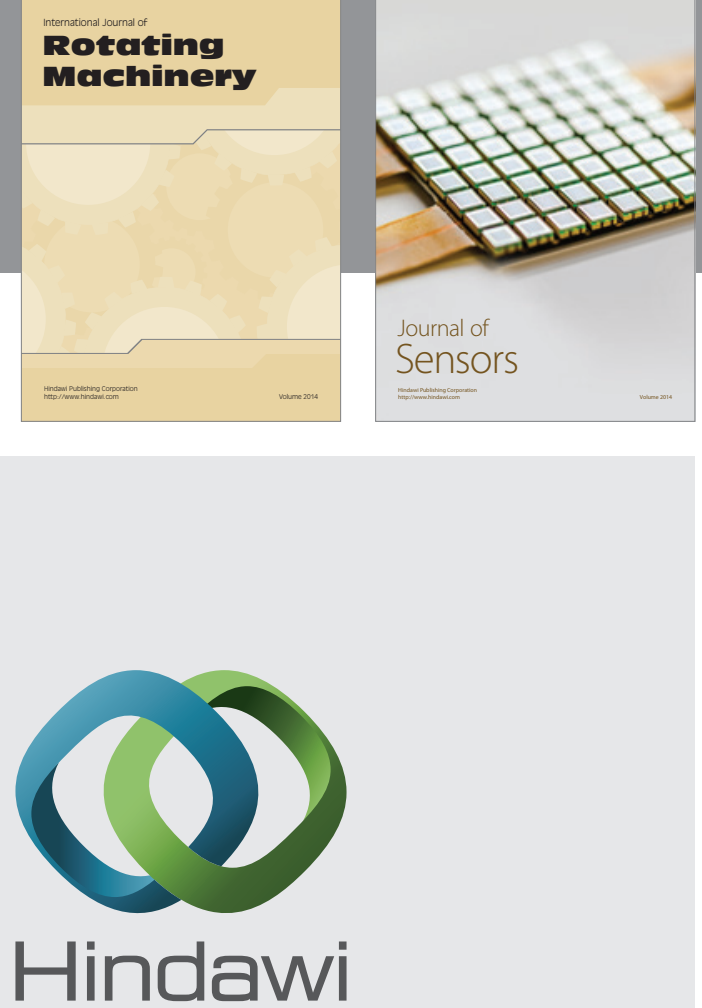

Submit your manuscripts at http://www.hindawi.com
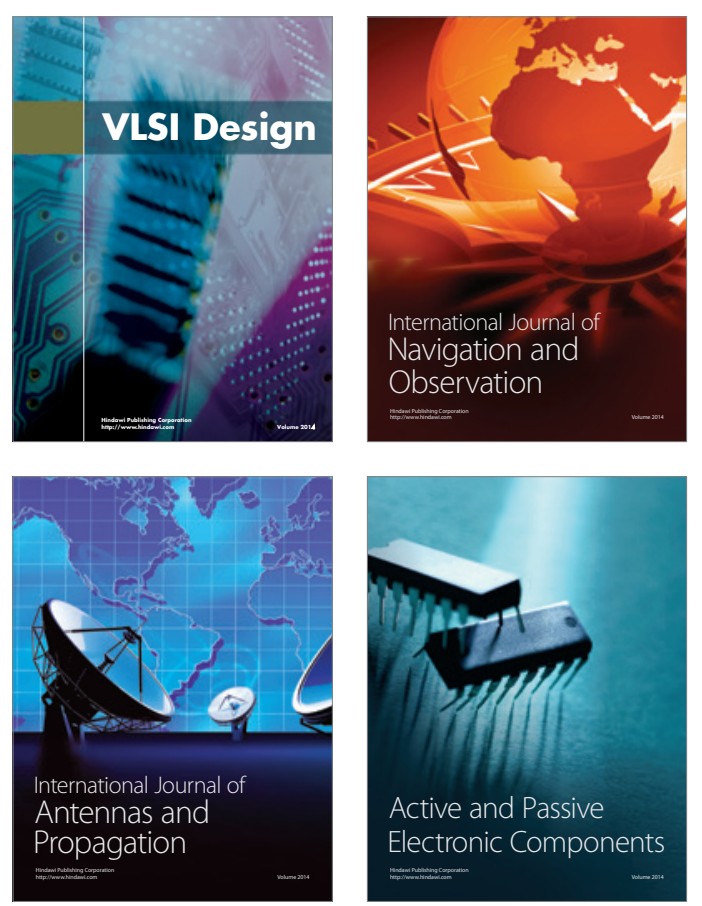
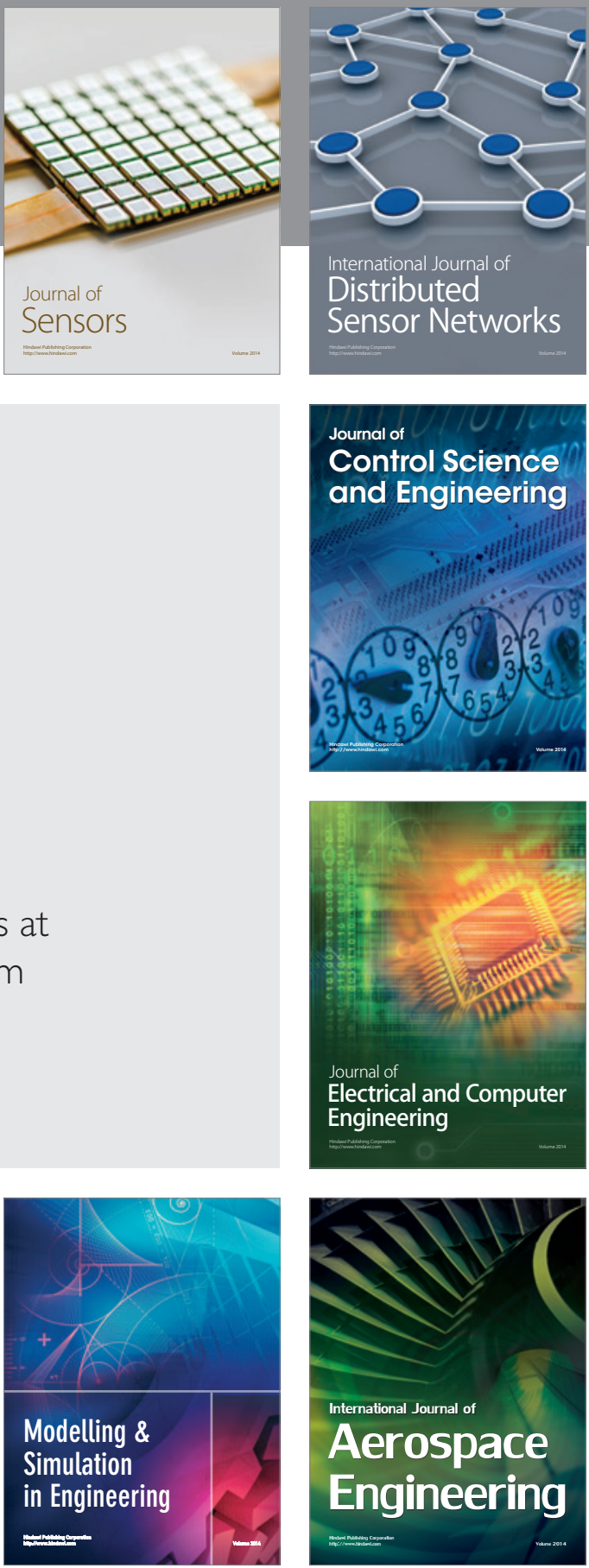

Journal of

Control Science

and Engineering
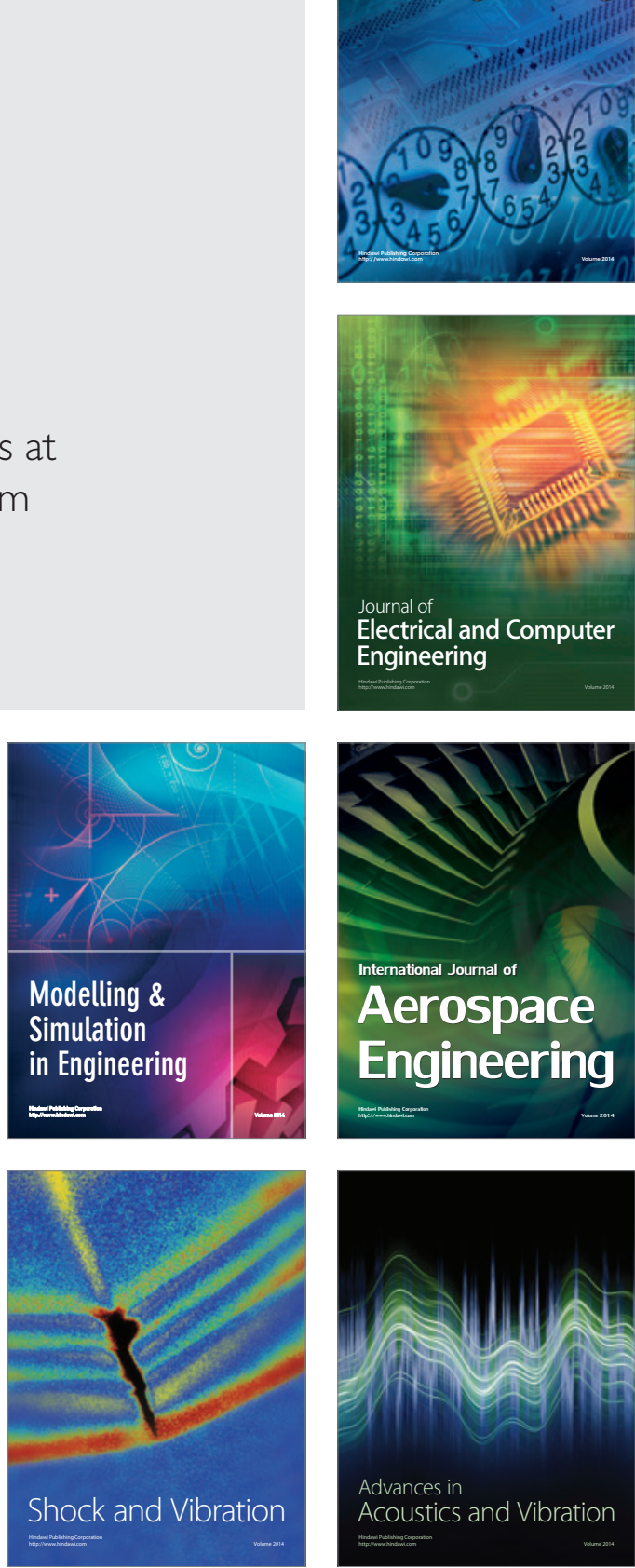